\title{
Experimental Study on Retrofitted RC T-BEAM Using FRP
}

\author{
N.Jasmine $^{(1)}$, S. Hemavathi( ${ }^{(2)}$, B.N. Brinila Bright ${ }^{(3)}$, M.B. Shanmuharajan ${ }^{(4)}$ \\ (1) PG Scholar, Department of Civil Engineering, Mohamed Sathak A.J College of Engineering, \\ Chennai-603103, Tamil Nadu, India. \\ (2),(3),(4)Faculty, Department of Civil Engineering, Mohamed Sathak A.J College of Engineering, \\ Chennai-603103, Tamil Nadu, India
}

\begin{abstract}
Retrofitting is the method of strengthening of accessible structure to build them more challenging to earthquake activity etc. Fiber Reinforced Polymer (FRP) composite was acknowledged in the building trade as alternate for repair and for accelerating the potency of RCC. This paper presents an investigational study on retrofitting of reinforced concrete beams using FRP.
\end{abstract}

Keywords:- Fiber reinforced polymer, Retrofitting etc.

\section{INTRODUCTION}

Humankind has been conscious of the complex resources since quite a few hundred years before Christ and useful invention to get better the excellence of living. In the field of repair of existing structures, the materials successfully integrate with the aged ones, forming a complex structure accomplished of prevailing contact to service loads, environment and time ${ }^{(1)}$.Composite forms varied structures, which convene the necessities of exact propose and purpose. Fresh types of composites are being made-up all the time with their own exact reason. Fibers fixed in medium of an additional material would be the excellent illustration of recent day composite materials, which are typically structural. Reinforcing materials usually endure utmost load and give out the logical properties. Solids that hold pressure to amalgamate other constituents supply sturdy bond for the reinforcing phase. A few dead resources, polymers and metals have established applications as medium materials in the conniving of structural composites, with admirable success. These materials stay elastic till collapse occurs and decreased collapse strain, when overloaded in stress and compression.

\section{$>$ Polymer matrix materials}

Polymers made perfect materials as they can be processed simply have lightweight $\&$ attractive automatic properties. It is there for the high temperature a resin is widely used in aeronautical function. Two significant kinds of polymers are thermosets and thermoplastics. Thermosets are very stretchy. Thus, they are the majority acted as medium bases for superior circumstances fiber reinforced composites. Thermosets are the the majority well-liked of the fiber composite matrices in the growth in structural engineering field could get shortened.

\section{$>$ Reinforcement}

Reinforcements for the composite can be fibers or fabrics particle. Among these fibers is the significant group of reinforcement. Fiber is characterized by one very extended axis with other two axes either often round or nearly spherical. A reinforcement that exaggerates the medium control must be stronger, stiffer than medium, and capable of changing malfunction mechanism to the advantage of the compound ${ }^{(2)}$. This means that the ductility should be smallest amount or even zero and the composite must behave as easily broken as possible. Glass fibers are the first known fibers used in escalation materials. Its length, shape, composition and direction of the fibers and the mechanical properties of the medium judge the performance of a fiber composite. The track of the fiber in the medium is a sign of the power of the composite and the strength is most along the longitudinal track of fiber. The premium performance from longitudinal fibers can be obtained if the load is applied along its direction. Since they have elevated strengths and low densities, the fiber length of filaments or other fibers yield considerable influents on the mechanical properties as well as the retort of composite to dispensation and events. Shorter fibers with appropriate direction composites that use coir, and glass fibers can be able with noticeably advanced strength than those that use incessant fibers. The considerable unwilling to the deterioration and elevated strength to weight ratio of FRP composites are their well known reward, due to which it has become famous escalation method of structures ${ }^{(3)}$. All the retrofitted beams showed important boost in ductility ratio and in power, absorption ${ }^{(4)}$.The FRP sheets are used outwardly wounded to the member and the number of layers of FRP is determined based on potency required. These applications give admirable shear and flexural strength to beam ${ }^{(5)}$.

\section{MATERIALS AND METHODS}

\section{$>$ Cement}

Cement is the largely vital component in a concrete mix. For this task, Ordinary Portland cement (OPC) of 53 Grade was used. The use of high-grade cement offers 10 to $20 \%$ reserves in cement use in addition to eminent strength. Laboratory tests were conducted on cement to resolve its standard consistency, initial setting time, final setting time, fineness and specific gravity. 


\section{Fine aggregate}

Artificial sand having specific gravity 2.706 was taken as fine aggregate. Sieve analysis of fine aggregate was also taken as per IS 383 (Part III)-1970 to conclude its grading prototype.

\section{Coarse Aggregate}

Nearby obtainable compressed stones were used for casting of concrete. Aggregates of sizes of $10 \mathrm{~mm}$ and 20 $\mathrm{mm}$ were used. The material fulfilled IS 383-1970. The specific gravity of $20 \mathrm{~mm}$ was 2.72 .

\section{$>$ Epoxy Resin}

Epoxy resins are comparatively small molecular weight pre-polymers. In civil industry, for covering and bonding reason epoxy resins are used. The epoxy resin is two-part arrangement, resin as paste and hardener as medium. The hardener and resin used in this study are Hardener HY. 951 and Araldite LY. 556.

\section{Composite}

The fiber-reinforced materials with polymeric matrix (FRP) can be measured as heterogeneous, anisotropic materials with a linear elastic performance up to collapse form. They are mostly used for strengthening of civil structures. There are a lot of compensation of using FRPs: lightweight, corrosion-resistant, good mechanical properties, etc. Fiber reinforced polymer (FRP) is a compound fabric made by amalgamation two or more resources to give a new mixture of properties. Yet, FRP is dissimilar from other composites in its ingredient materials that are dissimilar at the molecular stage and are automatically divisible. The automatic and physical properties of FRP are arranged by its structural configurations and ingredient properties even at micro level.

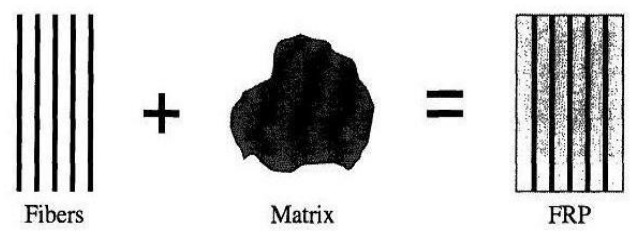

Fig 1:- Formation of Fiber Reinforced Polymer Composite

- Fiber:

A fiber is a fabric made into the length of filament with a diameter in the order of $10 \mathrm{tm}$. The major functions of the fibers are to capture the load and give influence, stiffness, thermal constancy in the FRP.

\section{$>$ Coir (Coconut Fiber)}

Coconut fiber is obtained from the husk of the crop of the coconut palm; the fibers are physically powerful, light and simply endure salt water and heat. Coir is an plentiful, adaptable, contemptible, and ecological cellulosic fiber used for manufacture of a wide variety of goods. Coir has also been experienced as reinforcement or as filler in different composite materials. Coconut coir is the majority attractive goods as it has the lowest bulk density and heat conductivity. The adding up of coconut coir abridged the heat conductivity of the composite specimens and obtainable a lightweight product.

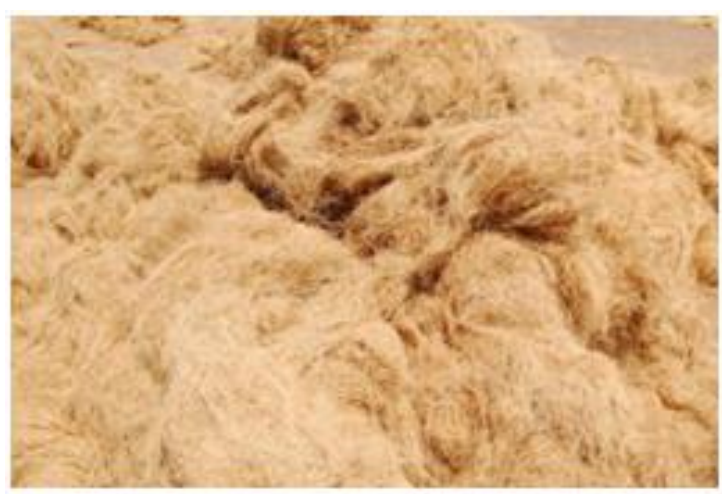

Fig 2:- Coir Fibre

\begin{tabular}{|c|c|}
\hline Properties & Values \\
\hline Specific gravity $\left[\mathrm{Kg} / \mathrm{m}^{3}\right]$ & 1174 \\
\hline Water absorption $[\%]$ & 91 \\
\hline Tensile strength $[\mathrm{MPa}]$ & $96-117$ \\
\hline Modulus of elasticity $[\mathrm{GPa}]$ & 7 \\
\hline
\end{tabular}

Table 1:- Properties of Coir fiber

\section{Glass Fiber}

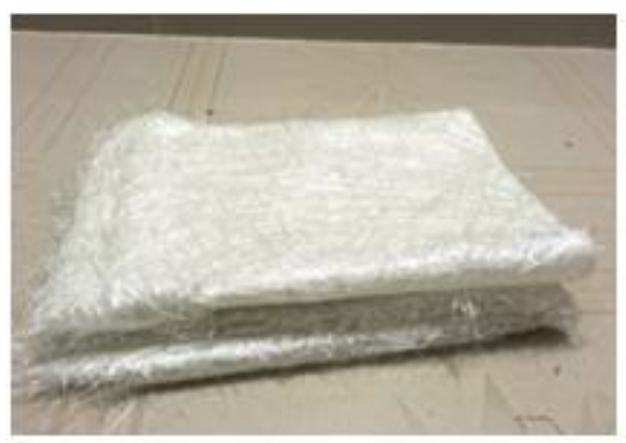

Fig 3:- Glass fiber

These fibers are commonly used in industrial fields to create composites of medium-high routine. Their exclusive feature is their lofty potency. Glass fibers typically have a Young's modulus of elasticity (70 GPA for E-glass) lesser than carbon fibers and their scrape confrontation is very poor; therefore, care in their exploitation is compulsory. In adding up, they are disposed to creep and have small low energy strength. To improve the connection between medium and fibers, as well as to look after the fibers itself next to dampness and alkaline agents, fibers experience sizing treatments acting as combination agents. Such treatments are helpful to improve low energy routine (static and dynamic) and sturdiness of the compound material. The FRP composite based on fiberglass are typically denoted as GFRP. 


\section{TESTING OF MATERIAL PROPERTIES}

For the preparation of concrete mix, the following material where used and their tests were conducted

\section{Cement}

\begin{tabular}{|c|c|}
\hline Name of The Test & Result of The Test \\
\hline Fineness test & $7 \%$ \\
\hline Consistency & $33 \%$ \\
\hline Initial setting time & 70 minutes \\
\hline
\end{tabular}

Table 2

Fine aggregate

\begin{tabular}{|c|c|}
\hline Name of The Test & Result of The Test \\
\hline Sieve analysis & Fineness modulus $=4.69$ \\
\hline Specific gravity & 2.706 \\
\hline
\end{tabular}

Table 3

\section{Coarse aggregate}

\begin{tabular}{|c|c|}
\hline Name of The Test & Result of The Test \\
\hline Sieve analysis & Fineness modulus $=5.52$ \\
\hline Specific gravity & 2.75 \\
\hline
\end{tabular}

Table 4

\section{PREPARATION OF COMPOSITES}

Materials used for the grounding of composites were plain weave glass fiber fabric, epoxy resin and hardener. Fiber fabric are sheet of layers of fiber made by mechanical inter locking of fiber themselves or with a minor fabric to close this fibers together and grasp them in place, giving the congregation enough dependability to be handled. Fabric types are categorized by the orientation of the fibers: unidirectional, $0 / 90^{\circ}$, Multi axial, and other /random. The orientation and weave style of the fiber fabric was chosen to optimize the strength and stiffness properties of the resulting material. Mainly usually used interlace method of $0 / 90^{\circ}$ cloth is plain interlace that gives much power.

\section{CASTING}

The dimensions of all beams are identical. The length of the beams was $1000 \mathrm{~mm}$ and cross sectional dimensions for flange portion $(1000 \times 180 \times 50) \mathrm{mm}$ and for web portion (1000x120x100) mm. Mild steel bars of 8mm diameter are used for longitudinal reinforcement.

\section{EXPERIMENTAL STUDY}

The specimens are experienced in the universal testing machine to find ultimate load. The test procedures of all the specimens are same. After the curing period of 28 days is over control beams are washed and is cleaned with dry clothes for clear visibility of cracks were other sets of beam are strengthened by glass fibers. The modulus of rupture was calculated using the equation, $\mathrm{M} / \mathrm{I}=\mathrm{F} / \mathrm{Y}$. The area under load-deflection gives toughness.

\section{RESULTS AND DISCUSSIONS}

\section{Flexural strength Test and Results}

The table shows the ultimate load, average ultimate load, modulus of rupture, average modulus of rupture , toughness of control beam, RC $\mathrm{T}$ beams retrofitted with coir and glass fiber and load carrying capacity is maximum in case of GFRP and coir in case of natural fiber.

\begin{tabular}{|c|c|c|c|c|c|c|}
\hline Specimen & Specimen No & $\begin{array}{l}\text { Ultimate Load } \\
\text { (KN) }\end{array}$ & $\begin{array}{l}\text { Ultimate Load } \\
\text { (Avg) }\end{array}$ & $\begin{array}{c}\text { Modulus of } \\
\text { Rupture } \\
\text { (MPa) }\end{array}$ & $\begin{array}{c}\text { Modulus Of } \\
\text { Rupture } \\
\text { Avg (MPa) }\end{array}$ & Toughness \\
\hline \multirow[t]{3}{*}{ Control Beam } & $\mathrm{SC} 1$ & 52 & \multirow{3}{*}{52.66} & 0.020 & \multirow{3}{*}{0.0203} & \multirow{3}{*}{227.8} \\
\hline & $\mathrm{SC} 2$ & 53 & & 0.020 & & \\
\hline & $\mathrm{SC} 3$ & 53 & & 0.020 & & \\
\hline \multirow{3}{*}{$\begin{array}{l}\text { RC Beam With } \\
\text { Coir Fiber }\end{array}$} & SCR1 & 56 & \multirow{3}{*}{63.66} & 0.021 & \multirow{3}{*}{0.0246} & \multirow{3}{*}{963.7} \\
\hline & SCR2 & 63 & & 0.024 & & \\
\hline & SCR3 & 72 & & 0.027 & & \\
\hline \multirow{3}{*}{$\begin{array}{l}\text { RC Beam With } \\
\text { Glass Fiber }\end{array}$} & SG1 & 61 & \multirow{3}{*}{65.33} & 0.023 & \multirow{3}{*}{0.0252} & \multirow{3}{*}{371.6} \\
\hline & SG2 & 69 & & 0.026 & & \\
\hline & SG3 & 66 & & 0.025 & & \\
\hline
\end{tabular}

Table 5:- Flexural Strength Test and results 
Graph showing variation of ultimate load for each specimen

From the graph, ultimate load carrying capacity is maximum for beams retrofitted with glass fiber and its $65.33 \mathrm{KN}$

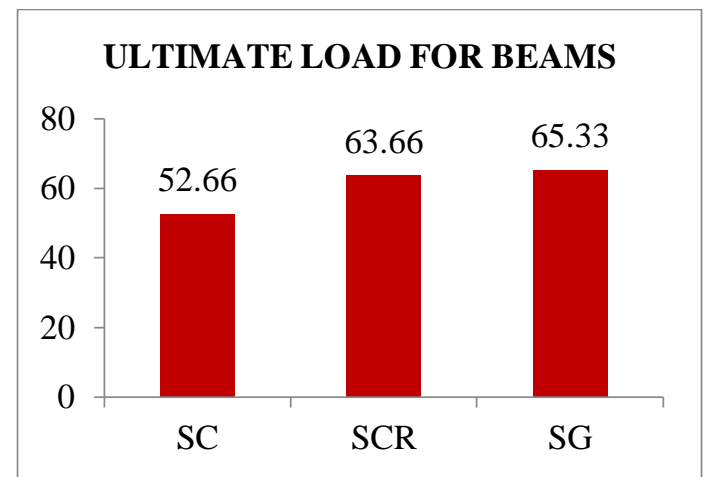

Fig 4:- Graphical representation of ultimate Loads for all beams

\begin{tabular}{|c|c|c|}
\hline Specimen & $\begin{array}{c}\text { Ultimate } \\
\text { Load } \\
\text { Avg(KN) }\end{array}$ & $\begin{array}{c}\text { \% Increase In The } \\
\text { Load Carrying } \\
\text { Capacity }\end{array}$ \\
\hline Control Beam (SC) & 52.66 & - \\
\hline $\begin{array}{c}\text { RC Beam With } \\
\text { Coir Fiber (SCR) }\end{array}$ & 63.66 & $20.88 \%$ \\
\hline $\begin{array}{c}\text { RC Beam With } \\
\text { Glass Fiber(SG) }\end{array}$ & 65.33 & $24.06 \%$ \\
\hline
\end{tabular}

Table 6:- Percentage increase in the ultimate load carrying capacity

This table shows ultimate load and percentage increase in the ultimate load carrying capacity of $\mathrm{RC} T$ beam and $\mathrm{RC} \mathrm{T}$ beam retrofitted with coir and glass fibers. It is seen that ultimate load is more in beam retrofitted with glass fiber. It is $24.06 \%$ more than the ultimate load carrying capacity of the control beam.

\section{LOAD Vs DEFLECTION CURVES}

Here the load is taken in $\mathrm{Y}$ axis and deflection is taken in $\mathrm{X}$ axis. The figures below shows the behavior of normal beam, beams retrofitted with coir and glass fiber.

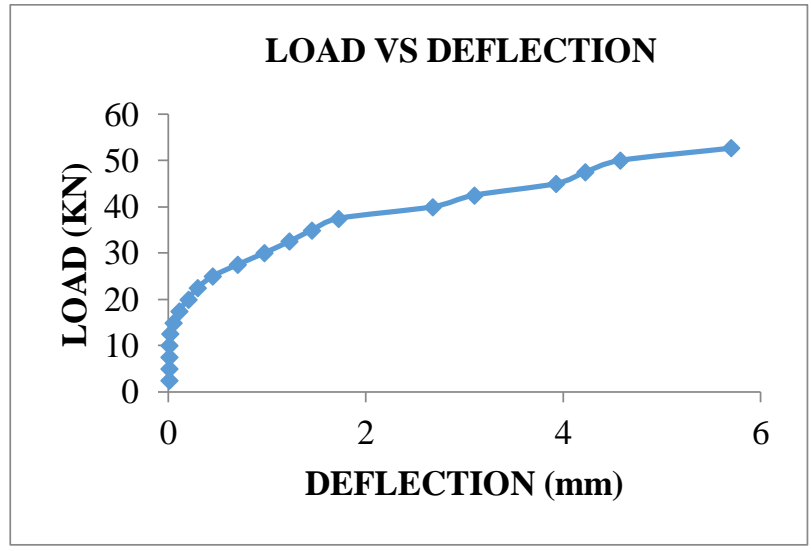

Fig 5:- Load Vs Deflection curve of normal beam

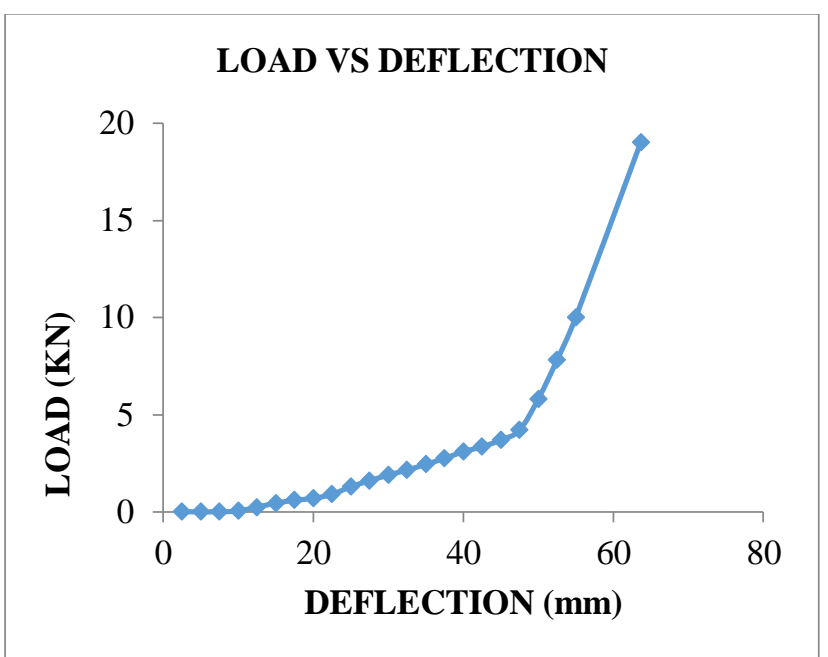

Fig 6:- Load Vs Deflection curve of beam retrofitted with coir fiber.

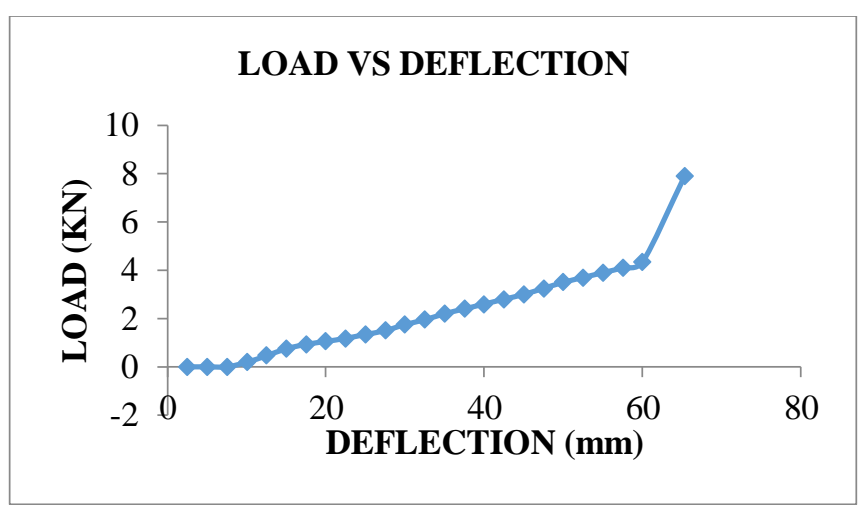

Fig 7:- Load Vs Deflection curve of beam retrofitted with glass fiber.

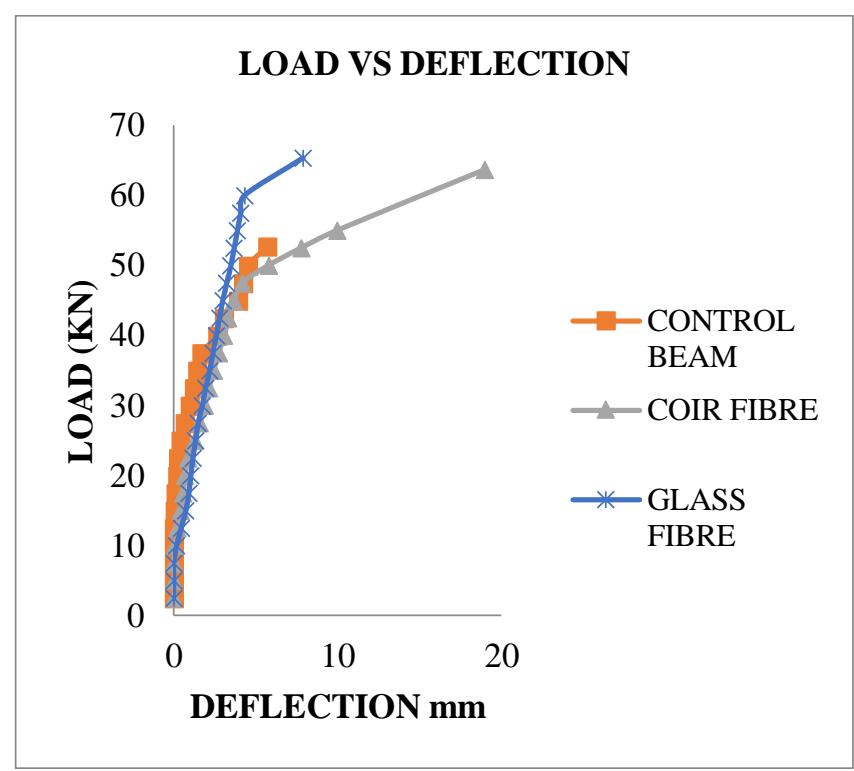

Fig 8:- Load-Deflection curve for all materials. 


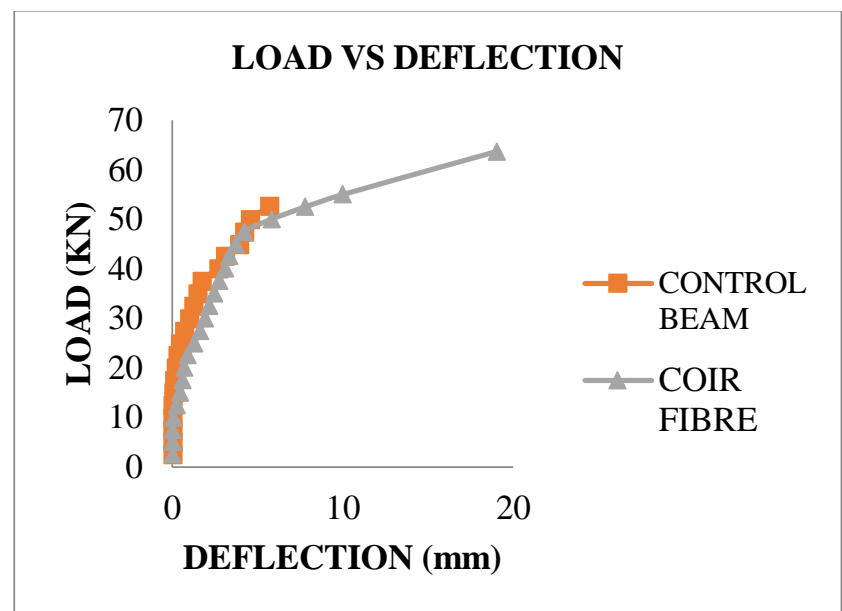

Fig 9:- Load Deflection curve of control beam and beam retrofitted with coir fiber.

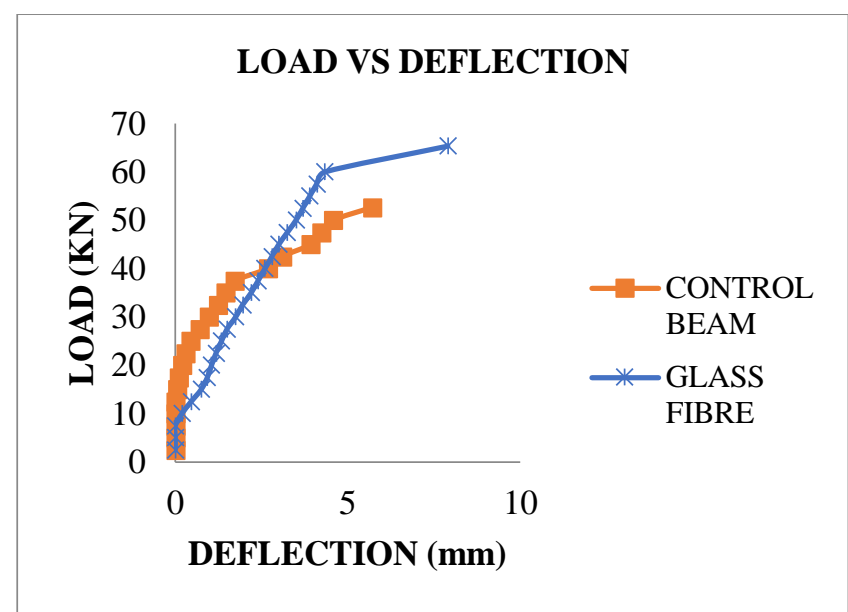

Fig 10:- Load Deflection curve of control beam and beam retrofitted with glass fiber.

From the load deflection curve of control beam and $\mathrm{RC}$ beam retrofitted with coir, glass fibers it is clear that retrofitted beam showed high ultimate load compared to normal beam. RC beam retrofitted with glass fiber having high load carrying capacity and its about $65.33 \mathrm{KN}$. It is $24.06 \%$ more than the ultimate load carrying capacity of control beam.

\section{CONCLUSION}

From the experimental flexural test results of 9 beams including 3 control beams and 6 retrofitted beams using FRP, the following conclusions have drawn.

The ultimate load was found to be elevated for beams strengthened with FRP composite than control beam.

$>$ Modulus of rupture also be found to be elevated to be elevated for RC beams retrofitted with fibers such as glass and coir corresponding to ultimate load

This showed that the use of both natural and artificial FRP was very effective in case of flexural strengthening of beams.

The load-deflection behavior was better for beams strengthened with FRP compared to the control beams.
The retrofitted beams with glass fiber having $24.06 \%$ more strength than control beams.

It shows that glass FRP has great probable in increasing the ultimate load of $\mathrm{RC}$ beams and enhances the material efficiency.

Among natural fibers, coir fibres have high load carrying capacity.

\section{REFERENCES}

[1]. An experimental study on retrofitted fiber-reinforced concrete beams using acoustic emission, A. Carpinteri, G. Lacidogna, A. Manuello, Department of Structural Engineering and Geotechnics, Politecnico di Torino, Italy

[2]. International Journal of Engineering Research \& Technology (IJERT) Vol. 2 Issue 1, January- 2013 ISSN: 2278-0181, Retrofitting of RC Beams Using FRP, Asst. Prof. Anumol Raju Mookambika Technical Campus, Asst. Prof. Liji Anna Mathew Toc $\mathrm{H}$ institute of Science \& Technology- retrofitting incess stiffness

[3]. Experimental Study on Shear Behavior of FRP Retrofitted T-Beams, Sainath B Tole1, Dr. B. Shivakumaraswamy 2, Dr. S.Vijaya 3, M.Tech Student1, Professor and Head 2, Professor 3, Dr. Ambedkar Institute of Technology, Bengaluru, India.

[4]. P Raghunathapandian, Dr. B. Palani, Dr. D. Elango. IJCIET Volume 8, Issue 11, November 2017

[5]. A Review Of Application Of GFRP In Shear And Flexure To Strengthen The Reinforced Concrete Beam ,Vineet Sharma1, Yudhvir Yadav2, PG Student, Department of Structural Engineering, CBS college, Jhajjar, Haryana, India, Assistant Professor, Department of Structural Engineering, CBS college, Jhajjar, Haryana, India 